\title{
Generation $Y$ and the World of Work in the Future
}

\author{
Prof. Kerstin LIESEM, PhD \\ Department of Communications, Faculty of Journalism and Communications \\ University of Media, Economics and Communications, University of Applied Sciences, \\ Cologne, (Hochschule für Medien, Kommunikation und Wirtschaft, Köln) \\ E-mail: k.liesem@hmkw.de
}

\begin{abstract}
The Digital Revolution and its effects have been changing the world of work. This paper explores the way in which processes of mediatization affect the working life of Generation Y. Especially against the backdrop of an anticipated labor shortage in Germany, Generation $Y$ and their attitudes to work will shape the German economy. Based on 24 guided interviews, this paper analyzes how Generation $Y$ handles the challenges of a mediatized world.
\end{abstract}

Keywords: Mediatization, Digitalization, Generation Y, World of Work.

\section{Introduction}

Every generation has its unique defining characteristics, and Generation $Y$, also known as Digital Natives, Net Generation, Generation@ or Millennials, is the generation which has grown up with the Internet. Generation $Y$ is the term given to the generation succeeding Generation $X$ and preceding Generation Z. Hence, Generation $Y$ refers to a specific generation born from the early 1980s to the mid-1990s. However, experts neither agree on an exact year when the era of Generation $Y$ started nor do they claim a distinct year to mark an endpoint of the era. However, what definitely sets apart Generation $Y$ from their forerunners is the fact that they grew up alongside mediatization and globalization. 
The definition of a whole generation inevitably inspires passionate debates as individuals are different concerning their social, cultural and economic backgrounds. Some scientists even refuse to accept the concept of generations. In their eyes it is virtually impossible to apply one definition to all as it comprises a range of diverse people. However, according to scientific literature portraying Generation $Y$, there are some characteristics which individuals of Generation $Y$ obviously have in common and which set them apart from previous generations. Individuals of Generation $Y$ differ in terms of attitudes, values and behavioral patterns from their predecessors. As a consequence, they tend to question strict hierarchies and entrenched structures. Although they are described as ambitious and determined, they appreciate a proper work-life balance. Unlike previous generations they are no longer willing to sacrifice their family lives to their careers. Hence, they expect employers to ensure the reconcilability of family and working life. Having grown up in a multioption society, Generation Y expresses a great need for individualism and flexibility, not only in their private lives, but also in their working environments.

As Generation $Y$ ascends the career ladder now and in the years to come, they are already influencing German companies and human resources managers. Especially against the backdrop of an anticipated labor shortage, Generation $Y$ and their attitudes will shape the German economy. This article will contribute to an analysis of Generation Y, not only in terms of their chances and choices, but also by identifying the stumbling blocks which might stand in their way when it comes to making a career.

\section{Theoretical framework}

In recent years, mediatization has emerged as an important concept and theoretical framework for considering the interplay between media, culture and society. Some of the most prevalent researchers in mediatization are noted to be Andreas Hepp, Stig Hjarvard, Friedrich Krotz and Knut Lundby (Lunt and Livingstone, 2016). Although the idea of mediatization dates back to the beginning of the 20th century, the current concept was not outlined before the last decade (Ekström et al., 2016; Hepp, 2013). However, the researchers have not yet reached a consensus about a comprehensive definition of mediatization (Deacon and Stanyer, 2014; Hepp et al., 2015). On the one hand, there are researchers who consider that the concept is based on the institutionalist tradition. On the other hand, there are those who argue that mediatization is based on the socio-constructivist tradition (Hepp, 2013; Birkner, 2015).

If mediatization was based on institutionalism, larger and smaller scale institutions, agencies and organizations would shape and regulate the communicative practices of media and the audience would need to adapt to the media and its objectives (Deacon and Stanyer, 2014; Hepp, 2013; Strömbäck and Van Aelst, 2013). 
This understanding is contrasted by disciples of the socio-constructivist tradition. One distinctive feature of the socio-constructivist approach is that it takes into account the change of the audience as well. The media and the media audience are both constantly changing and this approach aims to relate these changes to each other (Hepp, 2013; Hepp et al., 2015). Hence, Hepp et al. (2015) discussed the importance of the change of both sides, but also the "social dynamic that resists change" (Hepp et al., 2015, p. 317) as not all actors in society are willing to adopt new technologies or the current media logic. Hence, according to the socioconstructivist tradition, mediatization can be argued to be another model for socialization, as people can have the ability to communicate, share their ideas and be part of communities via media and technology (Deacon and Stanyer, 2014).

Having that in mind, mediatization is related to technological advancements (Hepp, 2013). Encheva et al. (2013, p. 10) defined how "the term mediatization describes the co-articulation of social and cultural changes on the one hand and changes in media and communication on the other". With the increase of different types of technological and mobile devices, more and more people can access the media from anywhere in the world. Consequently, mediatization is also correlated with the theory of the public sphere, as the citizens have increased access to the information and hence, the media (Ekström et al., 2016; Laursen and Valentini, 2015). As a result, mediatization explains how societies, cultures and people become influenced and shaped by media and technologies (Hepp, 2013) and how technologies and media might proceed to control and have power over people, their behavior and thoughts (Lunt and Livingstone, 2016). For example, the media have the potential to shape the views of its audience. With mediatization, it is even more effortless, as the Internet provides a technology that allows for simple, cheap, and worldwide distribution, [...] a short publication lag-time [...] which provides for interactivity and intertextuality (Encheva et al., 2013, p. 19).

\section{Methodology}

\section{Research design}

The study is based on the following research-leading question: What impact does mediatization have on the world of work of individuals of Generation Y? The insights the study provides are to be seen against the backdrop of social constructivism. That means that there is not one objective truth "waiting to be uncovered through positivist scientific inquiry" (Fairhurst and Grant, 2010). Hence, the study does not mirror reality; rather it creates it. Firstly, it is shaped by the insight of the author. Secondly, the reality of the interviewees must be seen as constructed as well (Flick 2002, p. 49). As a consequence, the scientific exploration does not strive for a description of reality. Instead, it aims at showing how reality is seen by the interviewees. 
To answer the research-leading question in all its complexity, I used guided interviews as research method, as they provided me with a wealth of personal information from the interviewees. The questions were consciously formulated in a very open way so that the interviewees had almost no restrictions in telling their stories. "People who openly and frankly tell their stories are a wealthy source of information and data for the researcher" (Roth-Ebner, 2015, p. 129). The study is based on 24 guided interviews amongst German individuals of Generation Y. The interviewees came from widely differing sections of society and backgrounds. To ensure that all interviewees were able to reflect their perceptions and observations as "experts of the situation", I chose people who have regularly dealt with modern communications technology both in their private lives and their working environment. The proportion of men and women was relatively equal. The interviews were conducted between February and June 2016.

The interviews were evaluated with Grounded Theory, a concept which was first published by the American sociologists Barney Glaser and Anselm Strauss in 1967 (Glaser and Strauss, 1967). Grounded Theory is characterized by "Symbolic Interactionism" (Flick 2002, p. 270). This means that a researcher has to analyze the objects from the point of view of the subjects. Grounded Theory is known as a systematic methodology in the social sciences which aims at constructing a theory through the analysis of data. As a result, Grounded Theory operates almost in a reverse fashion from traditional social science research. Unlike traditional research, Grounded Theory is not based on hypothesis. It is quite different from the traditional model of research, where the researcher chooses an existing theoretical framework, and only then collects data to show how the theory does or does not apply to the phenomenon under study. A study using Grounded Theory is likely to start with a question, a perception or just with a collection of qualitative data. As researchers review the collected data, ideas and concepts become apparent. These ideas and concepts are tagged with codes, which have been extracted from data. As more data is collected, and as data is re-viewed, codes can be grouped into concepts and become the basis for new theories.

Grounded theory was used as method because it enabled an open and unbiased approach to the research field. As the impact of mediatization on the world of work is a field where little research has been carried out so far, Grounded Theory is an appropriate method as it is based neither on models nor on hypothesis. Through the constant reflection and re-construction of the categories it is highly unlikely that the researcher will overlook aspects and influencing criteria. However, this evaluation method is complex and time-consuming, which can be seen as a disadvantage. 


\section{Results}

\section{Use of media in an occupational routine}

In the world of work, Generation Y relies on modern means of communication and communication devices as they ensure digital networking. Especially desktop PCs including tools such as email, Skype and Evernote are of crucial importance for Generation Y. Significantly fewer rank mobile devices.

"For my work I use - in descending order - the desktop PC, the notebook, the IPad and then the IPhone." (IV 01, 40-41)

When asked how they would react, if they had to give up all modern means of communication, the answers were unequivocal:

"Nowadays, I cannot imagine working without modern means of communication. I would not know how I could do my work without a computer. This would surely make work much more difficult." (IV 15, 250-255)

"It would not work without modern communication devices. I would not know how to communicate and network with others." (IV 11, $341 \mathrm{f}$ )

The answers underline that digital means of communication have revolutionized the world of work. Internet and mobile devices are considered a matter of course for individuals of Generation Y. They can no longer imagine everyday working life without using modern means of communication. Some interviewees even argue that the loss of digital means of communication and techniques would mean the loss of their existence (IV 08, 219).

The more the subject is interconnected in a mediatized world, the more important are social networking sites like Facebook, XING or Instagram. These sites are mainly used for three purposes: Firstly, to establish networks for the professional future, secondly, to cultivate relations amongst colleagues and finally, to obtain information.

"I need XING to meet the needs of my job. (...) Besides, I have accounts on Twitter and Instagram which I do not use actively. In my job it is vital to have different accounts to have the possibility to look into all of them from time to time." (IV 03, 56-60)

The majority of the interviewees strive for a workplace with interconnected communication. This includes appropriate hardware, collaborative software as well as cloudworking possibilities.

"The workplace of my dreams would be an office with interconnected communication. For me it is of crucial importance to be able to work from anywhere, even from home. The workplace of my dreams is technically well equipped." (IV 24, $222 \mathrm{ff}$.)

On the basis of the interviewees' answers I concluded that for Generation $\mathrm{Y}$ modern means and tools of communication such as computers, the Internet or so- 
cial networking sites are indispensable to meet the needs of their working lives. The workplace of their dreams ensures an interconnected communication in the world of work.

\section{Communication in a working environment}

In a vocational context the personal discussion, the face-to-face communication, loses its significance. It is replaced by computer- and technology-based communication techniques. Generation $Y$ regards emails as most important instruments of communication. Other software plays a minor role when it comes to coordinating work processes (see IV 03, 70-74). Generation $\mathrm{Y}$ is very much used to non-personal communication, mainly through emails. The result is that they do not use personal communication, even when this would lead to faster answers. Non-personal communication, though, always runs the risk of giving rise to misunderstandings which can possibly delay communication processes. In addition, the study reveals that communication instruments which are easy to handle lead to the exchange of too many and partially unnecessary pieces of information.

"Stress occurs through the simplicity. Because it is so easy to write an email, an incredible amount of emails are written, even if they are totally unnecessary." (IV 01, $361 \mathrm{ff}$.)

In addition, it often happens that the communicator does not check the content of an email carefully before sending it, because he knows that it is quite easy to send another email shortly after, to elaborate on or clarify the previous one. This clearly shows that non-personal communication techniques encourage a less careful and less concentrated working style. In summarizing, it can be said: Generation $\mathrm{Y}$ experiences a habituation when it comes to non-personal communication instruments. They tend to use them without further consideration, which could pose a risk of a delay in communication processes.

\section{Advantages and disadvantages of modern communication technologies}

The study has shown that Generation $Y$ is well adapted to the mediatized world of work. They enjoy the advantages of the new technological possibilities (enormous speed, social networking, independence in terms of place and time, see IV 20, 64-65). For them, a future without digital media is not imaginable. As a negative aspect they often describe the constant availability.

"The constant availability is a problem, indeed. There are situations when you are annoyed because something at work does not function (...). Image the following situation: You are at home in the evening starting to relax. Then you get an email from your boss because something has happened. Then you have to deal with that problem in the evening." (IV 02, 526-528)

However, Generation $\mathrm{Y}$ is well aware that boundaries between private lives and work will increasingly blur, the more modern means of communication im- 
prove. They clearly see the risk that colleagues as well as superiors will not stop communicating after the end of the working day. They fear that they, as communication partners, could be put in a tight spot in the future.

In summary, it can be said that Generation $Y$ regards the constant availability as a burden. They clearly see and express the risk of blurring boundaries between work and private lives.

Constant availability is closely linked to information overload. The study highlights that Generation $Y$ has accepted the flood of information.

"I grew up with information overload. So, I feel well adapted to it, because I know how to deal with it." (IV 15, 215-218)

The majority of the interviewees argue that they are able to deal with information overload, because they have adopted the ability to differentiate relevant pieces of information from irrelevant ones. They claim to be able to prioritize. However, a large portion of the interviewees revealed that they would worry about missing something important, if they were not able to permanently update their communication channels. Consequently, people constantly feel under pressure, because they are in fear of missing some messages.

"I would say that the constant possibility to get information and to be informed about everything is more of a burden than a relief." (IV 21, 241-244)

The resulting pressure is worsened further when people bring their private gadgets like their smartphones to work. This has a negative effect on the individual working style, because it constantly distracts people from work. The permanent rechecking of the communication channels has virtually become an addiction, which the majority of Generation $Y$ has not come to grips with. The results of the interviews suggest that it is less the information overload which becomes a burden but rather more the constant pressure to receive all messages in real time. Although Generation Y complains about pressure, they do not take any countermeasures. It can therefore be concluded that even if interviewees claim to be able to deal with information overload, they do not come to grips with their addictive behavior. Although they cast a critical eye over their media usage, they do not take any countermeasures to get themselves out of their addiction.

\section{Discussion}

The permanent availability in the working environment triggers stress. According to a survey published by the German "Initiative for Health and Labor" (i.ga) in 2015 amongst 125 employees and people from their private environment a majority strives to avoid receiving any work-related messages during their vacation (see i.ga.Report 23:2015). Besides, a large portion of the interviewees argue 
for legal regulations and/or company agreements which ensure the separation of work and leisure.

It will be vital for the quality of the work in the future how companies will deal with the permanent distraction of their employees triggered by a constant flood of information and the compulsion of people to receive it in real time. As far back as in 2007 South Korean researchers came up with the term "digital dementia" as a result of the mediatized world (Chung-a; web). A study of the Website Incruit and the Research Company Embrain amongst 2000 employees aged between 20 und 30 years had revealed that young South Korean adults suffered from concentration problems as well as from attention deficits and memory disorders. In Germany, the term "Digital Dementia" is associated with brain researcher and psychiatrist Manfred Spitzer. He holds that the use of modern media will restrict the human brain structure (Spitzer, 2012).

Considering these findings, a responsible and health-oriented use of digital media on the side of the employees will be of major importance. What is even more important is the attempt to implement a responsible use of media in the culture of a company. What impact media literacy will have on the individual company is surely a question of company culture. At this point superiors take responsibility. They have to serve as role-models for a responsible use of digital media and they have to appreciate it as an enterprise value.

\section{Conclusion}

The interviews have shown that the use of digital means of communication is a matter of course for Generation $\mathrm{Y}$ as they cannot imagine an "analogue" world of work. What Generation Y does appreciate most is that mediatization enables worldwide networking and independence in terms of both time and space. The majority of the interviewees strive for a workplace with interconnected communication. This includes appropriate hardware, collaborative software and cloudworking possibilities.

Generation $Y$ has become accustomed to the permanent flood of information. Despite the positive basic mood concerning the mediatized world of work Generation Y does consider the disadvantages. They have recognized that a fast and straightforward communication, e.g. through emailing, has its drawbacks. It tempts users to use them without further considerations. The result seems to be paradoxical: Although people have access to fast means of communication their actual communication processes do not accelerate to the same extent. Besides, non-personal communication lacks gestures and facial looks. This also can be a source of misunderstandings which might delay the communication process.

Even if Generation Y claims to deal responsibly with information overload they recognize an addiction to their digital communication channels. This conduct 
conceals the permanent fear to miss something "important". Although they have noticed their addiction, the level of suffering has not become sufficiently high for them to request therapy of their own accord. Permanent distraction as well as constant availability hamper a proper work-life balance.

\section{References}

1. Birkner, T. (2015). Mediatization of politics: The case of the former German chancellor Helmut Schmidt. European Journal of Communication. 30 (4), 454-469.

2. Chung-a, P. (2007). Digital Dementia Troubles Young Generation; in: The Korea Times dated 8.06.2016. Retrieved from http://www.koreatimes.co.kr/www/news/ nation/2007/06/117_4432.html, accessed on December 12, 2016.

3. Deacon, D. and Stanyer, J. (2014). Mediatization: key concept or conceptual bandwagon? Media, Culture \& Society. 36 (7), 1032-1044.

4. Ekström, M., Fornäs, J., Jansson, A. and Jerslev, A. (2016). Three tasks for mediatization research: contribution to an open agenda. Media, Culture \& Society. 38 (7), 1090-1108.

5. Encheva, K., Driessens, O. and Verstraeten, H. (2013). The mediatization of deviant subcultures: an analysis of the media-related practices of graffiti writers and skaters. MedieKultur - Journal of media and communication research. 54, 8-25.

6. Fairhurst, G., Grant, D. (2010). "The Social Construction of Leadership: A Sailing Guide". Management Communication Quarterly. 24 (2): 171-210.

7. Flick, U. (2002): Qualitative Sozialforschung. Eine Einführung. Reinbeck b. Hamburg: Rowohlt.

8. Glaser, B., A. Strauss (1967). The Discovery of Grounded Theory; Strategies for Qualitative Research. New York: de Gruyter.

9. Hepp, A. (2013). The communicative figurations of mediatized worlds: Mediatization research in times of the 'mediation of everything'. European Journal of Communication. 28 (6), 615-629.

10. Hepp, A., Hjarvard, S. and Lundby, K. (2015). Mediatization: theorizing the interplay between media, culture and society. Media, Culture \& Society. 37 (2), 314-324.

11. i.ga. Report (2016). Psychische Belastung in der Arbeitswelt. Dresden. Retrieved from https://www.iga-info.de/fileadmin/redakteur/Veroeffentlichungen/iga_Re porte/Dokumente/iga-Report_32_Psychische_Belastung_in_der_Arbeitswelt.pdf, accessed on December 12, 2016.

12. Laursen, B. and Valentini, C. (2015). Mediatization and Government Communication: Press Work in the European Parliament. The International Journal of Press/Politics. 20 (1), 26-44.

13. Lunt, P. and Livingstone, S. (2016). Is 'mediatization' the new paradigm for our field? A commentary on Deacon and Stanyer $(2014,2015)$ and Hepp, Hjarvard and Lundby (2015). Media, Culture \& Society. 38 (3), 462-470. 
14. Roth-Ebner, C. (2015). Der effiziente Mensch. Zur Dynamik von Raum und Zeit in mediatisierten Welten. Bielefeld: transcript.

15. Spitzer, M. (2012). Digitale Demenz. Wie wir uns und unsere Kinder um den Verstand bringen. München: Droemer.

16. Strömbäck, J. and Van Aelst, P. (2013). Why political parties adapt to the media: Exploring the fourth dimension of mediatization. The International Communication Gazette. 75 (4), 341-358. 